\title{
Contribution of Arbuscular Mycorrhiza to Productivity of Barley on Contrasting Cropping Systems, in Central Greece
}

\author{
Dimitrios BESLEMES $^{1 *}$, Evangelia TIGKA ${ }^{1}$, Dimitrios VLACHOSTERGIOS ${ }^{1}$, Dimitrios BILALIS ${ }^{2}$ \\ ${ }^{1}$ Istitution of Industrial and Fodder Crops. Hellenic Agricultural Organization “DEMETER”, Theofrastou \\ 1 str. , 41335, Larisa, Greece. \\ ${ }^{2}$ Department of Agronomy. Agricultural University of Athens, Iera Odos 75, 11855, Athens, Greece. \\ *corresponding author, e-mail: d_beslemes@yahoo.gr
}

Bulletin UASVM series Agriculture 73(1)/2016

Print ISSN 1843-5246; Electronic ISSN 1843-5386

DOI 10.15835/buasvmcn-agr: 11818

\begin{abstract}
The objective of this study was to evaluate the effect of Arbuscular Mycorrhizal fungi inoculation on productivity of barley, under different levels of fertilization on organic or conventional agricultural systems. In addition, the mycorrhizal dependency of each system was studied for all fertilization levels. Experimental field was settled in central Greece, on clayey soil and experiments were conducted under real field conditions, in a split plot design. Two mycorrhizal treatments were combined with five fertilization treatments, in three replications. Growth parameters (e.g. plant height, total biomass production, seed yield, Leaf Area Index, Harvest Index) were monitored throughout cultivation period. Percentage of root AM colonization and mycorrhizal dependency were also measured for each treatment. Results indicated that AM inoculation had a positive effect on growth parameters and final productivity of barley. Plants of inoculated plots reached higher final height, higher LAI, and higher seed yield. Inorganic fertilization suppressed AM root colonization, especially when higher rates of inorganic fertilizers were applied. In contrast, organic fertilization did not suppressed AM colonization, especially in the case of AM inoculation. Mycorrhizal dependency was higher for the low-input cropping systems. In the present research work, we demonstrated that AM inoculation can positively affect growth and productivity of barley, in both organic and conventional cultivation.
\end{abstract}

Keywords: Arbuscular myccorrhiza, barley, cropping systems.

\section{INTRODUCTION}

Arbuscular Mycorrhizal fungi (AMF) are among the most important and influential soil microbes, significantly affecting the growth of plants and other soil microorganisms (Miransari, 2011). AM fungi are able to develop a symbiotic association with most terrestrial plants (Feddermann et al. 2010), thus the symbiotic association between mycorrhizal fungi and the roots of plants is widespread in the natural environment. There are a number of different types of fungi that form these associations, but for agriculture, it is the arbuscular mycorrhizal fungi of the Phylum Glomeromycota (Schussler et al., 2001) that are most important, able to form a symbiotic association with more than $80 \%$ of land plant families.

Crop management involves a range of practices which can impact on the AM association, both directly, by damaging or killing AMF and indirectly, by creating conditions either favorable or unfavorable to AMF. In general, agricultural practices have a negative impact on the AM association and agricultural soils are AMF impoverished, particularly in terms of numbers of species (Helgason et al., 1998; Menéndez et al., 2001). For example, in areas of intensive agricultural production, $\mathrm{P}$ fertilizer use has been well in excess of crop requirements, resulting in a build up of total and in some cases easily 
available $\mathrm{P}$ in the soil (Kogelmann et al., 2004). This has led, in turn, to less reliance of crops on the AM association and lower AM colonization and propagule density.

On the other hand the exclusion of soluble mineral fertilizers and the very limited use of biocides in organic agriculture mean that it is reliant largely on biological processes for supply of nutrients and AMF are usually considered to play an important role, as it is assumed that they can compensate for the reduced use of $\mathrm{P}$ fertilizers (Galvez et al., 2001). However, the actual importance of AMF to the functioning of organic agroecosystems and in particular to crop performance remains to be determined. Because the AM symbiosis can benefit plant growth and health, thereisanincreasinginterestin ascertaining its effectiveness in particular plant-production systems and, consequently, in manipulating them, when feasible, so that they can be incorporated into production practices. Evidence is accumulating to show that indigenous and/or introduced AM fungi can benefit annual crops, such as cereals (Azcon-Aguilar and Barea, 1997). Selection of the appropriate AM fungi (Estaïn et al., 2002) and the analysis of the ecological considerations of AM inoculation (Vosatka and Dodd, 2002) are critical issues for the application of mycorrhizal technology in agriculture.

Inoculation experiments have shown that different AMF species produce a wide range of growth responses in the host plant, from significantly positive to significantly negative (Kahiluoto et al., 2009). The task of selecting species to use in AMF inoculums is complicated by the fact that the most effective AMF species may differ between host plants and may depend on whether the main aim is nutrient uptake, increased pathogen resistance or improved water relations. Failure to find the most appropriate $\mathrm{AMF} /$ host/inoculation method may explain why some inoculants used thus far have failed to have a beneficial effect, even though degree of colonization may be high. Even where an effective $\mathrm{AMF} /$ host/inoculation combination is identified, there remains the problem of competition with the native soil AMF (Gosling et al. 2006).

The aim of this study was twofold: (i) to analyze the contribution of AMF inoculation as well as the contribution of field AMF communities to crop growth and productivity of cereals such as barley and enlighten the underlying mechanisms in contrasting cropping systems, (ii) to evaluate if these cropping systems can influence AM root colonization by either indigenous or inoculum introduced mycorrhizal population.

\section{MATERIALS AND METHODS}

a) Site, experimental design and crop agronomy.

The evolution of growth and final productivity of barley (Hordeum vulgare cv Triptolemos), were studied under field conditions in Central Greece (Thessaly plain, Larisa area, coordinates:

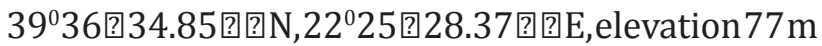
above sea level) over a period of one agricultural season (2014-2015), using a two factor (2X5X3) split plot experimental design in three blocks. Two treatments for AMF inoculation (AMF+= with inoculation, AMF- = without inoculation) were combined with five fertilization treatments $(100 \%$ org $=100 \%$ of recommended dose in organic form, $60 \%$ org $=60 \%$ of recommended dose in organic form, 100\%inorg $=100 \%$ of recommended dose in inorganic form, 60\%inorg= $60 \%$ of recommended dose in inorganic form, Control= no fertilization). Fertilization was applied in two doses. The first was applied at sowing as basal dressing with $50 \mathrm{~kg} \mathrm{~N} \mathrm{ha}^{-1}, 20 \mathrm{~kg} \mathrm{P} \mathrm{ha}^{-1}$ and $15 \mathrm{~kg} \mathrm{~K} \mathrm{ha}^{-1}$ in all plots for the $100 \%$ dose and the second dose (equal amount) was applied on the onset vegetative phase, when plant height was approximately at $50 \mathrm{~cm}$.

The study soil was silty-clayey to loamyclayey, classified as Vertisol (Soil Survey Staff, 2010), with average soil particle size distribution: clay $51 \%$, silt $23 \%$, sand $26 \%$, $\mathrm{pH}=7.2$, and organic matter content $1.6 \%$. Total available nitrogen in the soil was moderate $\left(\mathrm{N}_{\text {Kjeldhal }}: 0.09 \mathrm{~g} / 100 \mathrm{~g}\right)$ as well as available potassium $\left(\mathrm{K}_{\text {exch }}: 1.7 \mathrm{cmol}^{+} / \mathrm{kg}\right)$, while phosphorus availability was low $\left(\mathrm{P}_{\text {Olsen }}: 6.7\right.$ $\mathrm{mg} / \mathrm{kg}$ ).

Before planting, furrows $0.25 \mathrm{~m}$ apart were opened to a depth of approximately 7-10 cm and mycorrhizal inoculum was evenly distributed along the bottom of the furrows of the whole plot. AM fungi inoculum was placed in the furrows below the barley seeds and lightly covering with soil from the furrow on the day of planting. The inoculum used was a commercial mixture of six strains of Phylum Glomeromycot, consisted of AMcolonized root pieces and spores and hyphae in 
fritted clay. No inoculum was added to the control plots.

Planting arrangement was $25 \mathrm{~cm} \mathrm{x} 10 \mathrm{~cm}$ for barley $\left(160 \mathrm{~kg} \mathrm{ha}^{-1}\right)$. No irrigation was applied and crops were left rain fed. No macro-nutrient deficit, or water stress, were observed throughout the crop cycle.

b) Data collection and calculations.

Crop growth and aerial biomass productivity throughout the crop cycle was determined by field samplings. Growth parameters (plant height, specific leaf area and leaf area index) and aboveground fresh and dry biomass productivity per plant component (stem, leaves and storage organs) were measured in subsequent destructive harvests throughout the growing period, at fifteen days intervals. The harvested plots were spaced out in such a way as to avoid being influenced by previous sample collections. The plants were cut at the ground level. In each manual harvest, the sample was divided into the various plant organs and weighted fresh in the field. Then the samples were oven-dried at $70^{\circ} \mathrm{C}$ until constant weight $(2-4$ days) and weighted again in order to determine the dry weights per plant component. The blades of fully expanded leaves and the external part of the blades of not fully expanded leaves were included in the same leaf blade fraction. The leaf area of the total leaf sample was measured using high resolution scanned leaf images and ImageJ software.

From plant biomass and leaf area development data, and following an interval approach (Hunt, 1978), these fundamental growth parameters were calculated: leaf area index (LAI); specific leaf area (SLA); leaf weight ratio (LWR) and the integrated leaf area duration (LAD). Seasonal progression of growth and biomass parameters were depicted in a time scale of days after emerge (DAE).

Root samples were collected 140 days after sowing and from the $0-35 \mathrm{~cm}$ layer by using a cylindrical auger (25 cm length, $10 \mathrm{~cm}$ diameter) at the midpoint between successive plants within a row. Firstly, roots were separated from the soil by soaking the samples overnight in $30 \mathrm{ml}$ of a $0.5 \%$ solution of sodium hexametaphosphate. Afterwards, the samples were stirred for $5 \mathrm{~min}$ and washed over a $5 \mathrm{~mm}$ mesh-sieve. The roots thus held on the sieves were cleaned and stained with lactic acid/fuchsin, according to the method
Kormanik and McGraw (1982). The percentage of root length colonized by AM fungi was determined by fluorescence microscopy with the gridlineintersection method at a magnification of $\times 30$ 40 (Giovannetti and Mosse, 1980). Weighted Mycorrhizal dependency (WMD) was calculated according to a modified equation of Plenchette et al. (1983) as follows;

Weighed Mycorrhizal dependency (\%) = [( $($ dry weight of inoculated plant $\mathrm{x} \%$ colonization) - (dry weight of non- inoculated plant $x \%$ colonization))/ (dry weight of inoculated plant $\mathrm{x} \%$ colonization)] $\mathrm{X} 100$.

The modification incorporates the effect of indigenous AMF populations on crop production, since control plots (not inoculated) were not subjected to fungicide and therefore "hosted" native AMF populations. Indigenous AMF population was expected to colonize barley crops of control plots, suggesting that plants of these plots were only non-inoculated and not non-mycorrhizal.

All measured and derived data were subjected to analysis of variance (ANOVA), using the statistics software package SPSS Ver.17 (SPSS Inc, Chicago, Ill, USA), following the experimental design. All possible interactions of the respective data set were calculated using general linear model. As test criterion for detecting differences between means the $\mathrm{LSD}_{0.05}$ was used (Steel and Torrie, 1982) in order to allow multiple comparisons.

\section{RESULTS AND DISCUSSION}

a) Growth analysis

The results demonstrated a significant effect $(\mathrm{P}<0.05)$ of the AMF inoculation managements on all measured and estimated growth parameters for both fertilized and unfertilized crops as well as for organic and inorganic fertilization.

\section{i) Plant heights}

The growth analysis of barley as reflected by means of plant heights for each treatment is illustrated in Fig. 1. After a small lag phase of crop establishment the crop began the vegetative stage and it can be observed that initially all treatments, even control, produced similar growth rates (1.0$1.2 \mathrm{~cm} \mathrm{~d}^{-1}$ in height) to reach a height of about 40 $\mathrm{cm}$ by 50 days after emerge (DAE).

From this period and on, AMF inoculation significantly affected plant height that increased almost linearly until flowering (70 DAE), with 
higher growth rates for the plants of fertilized plots (viz. $1.8 \mathrm{~cm} \mathrm{~d}^{-1}$ ) as opposed to plants of unfertilized plots (viz. $1.0-1.2 \mathrm{~cm} \mathrm{~d}^{-1}$ ). A clear superiority of $\mathrm{AMF}+$ treatments on growth was also noticed in plots that full fertilization was applied, especially after the application of the second dose of fertilizer (55 DAE) when plants had already reached an average height of $50 \mathrm{~cm}$, since young barley plants are in need of adequate supply of nutrients for unobtrusive crop growth (Schröder, 1999).

The substantially higher growth rate of AMF inoculated plants was maintained until anthesis, resulting to higher final heights upon completion of the crop biological cycle, compared to noninoculated plants. For both AMF treatments, plants that received full $\mathrm{N}$ and $\mathrm{P}$ fertilization, reached greater final heights while plants without fertilization reached minor final heights, probably because of higher growth rate during the vegetative phase that was significantly affected by $\mathrm{N}$ fertilization. Positive effect of $\mathrm{AMF}+$ treatments $(\mathrm{P}<0.05)$ in final plant height was evidenced for low $\mathrm{N}-\mathrm{P}$ fertilized plots and for organic fertilization. Even plants of control (unfertilized) plots reached final heights close to those of fully fertilized plots. On the contrary, there were no statistical significant differences in growth rates and plant heights, final or mean, between the plants of $\mathrm{AMF}+$ plots that received inorganic or organic fertilization, suggesting that both fertilization practices have a similar positive effect regarding barley plant height.

\section{ii)Leaf area index}

Fig. 2 illustrates the development of leaf area index under the various inoculation methods and fertilizer application, throughout the growing period barley.

Leaf area expansion is of great importance for light interception and photosynthesis; it can be observed that leaf area expansion was also characterized by a lag phase of crop establishment, after which leaf area index increased rapidly until flowering initiation, in step with rapid crop growth rates, since late sowing insured optimum climatic conditions for vegetative phase.

During the lag phase, AMF inoculation affected significantly leaf area expansion monitoring higher LAI values for inoculated plots. There were also statistical significant differences $(\mathrm{P}<0.05)$ between the two fertilization type treatments during that phase, with plants of plots fertilized with organic fertilization reaching higher LAI values for both fertilization levels $1100 \%$ and $60 \%$ NPK). Oppositely, in non inoculated plots results suggested that higher LAI was measured in plots were inorganic fertilization was applied. During the vegetative phase, statistical significant differences $(\mathrm{P}<0.05)$ between the two AMF as well as between the type-level fertilization treatments

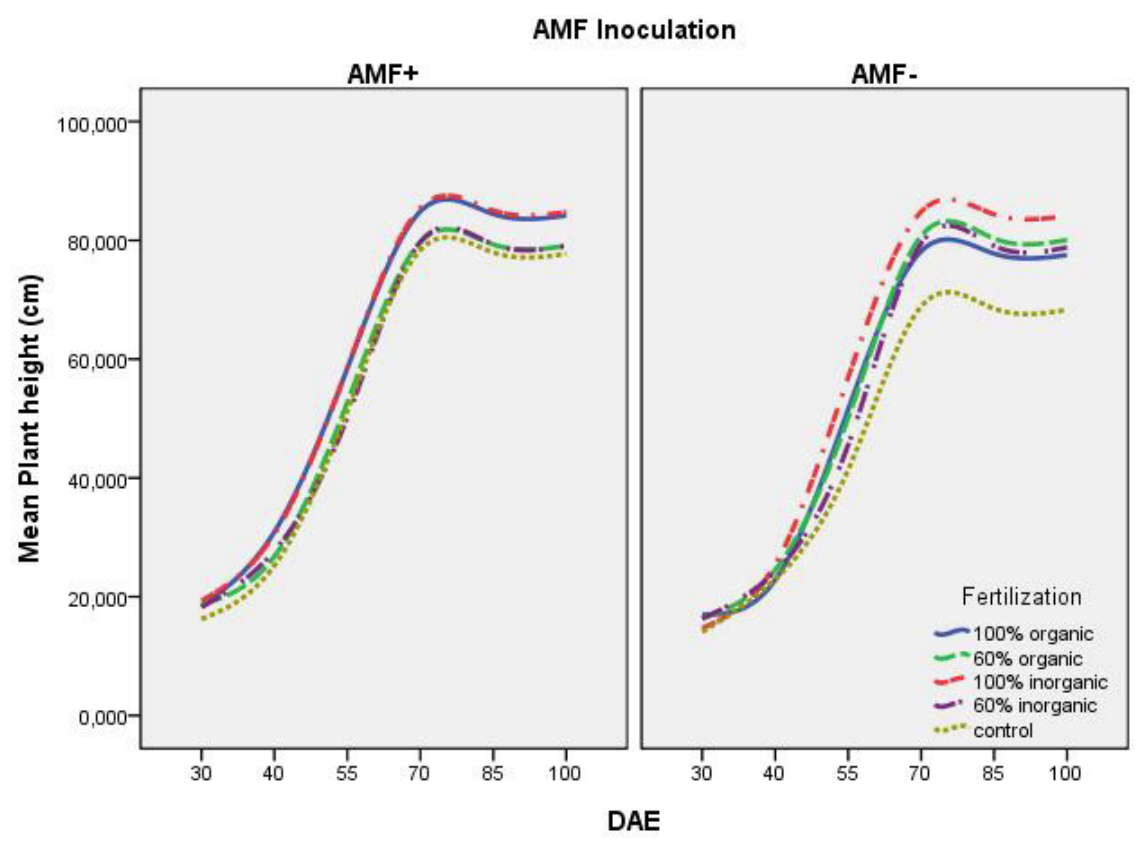

Fig.1. Plant height of barley plants as affected by AMF inoculation and fertilization type and level. 
were monitored, with higher LAI for AMF+ plots in all cases. The canopy results were already satisfactory by 50-55 DAE for both inorganic and organic fertilization (leaf area index $>3$ ), despite the positive impact of $100 \%$ inorganic fertilization on estimated LAI during the crop cycle, helping crop reach a closed canopy by 7-8 days earlier and higher final LAI. These differences lasted until the end of growing period (Fig. 2), when LAI decreased because assimilates was distributed to reproductive organs to support seed growth. In this period, descent of LAI in organic fertilization plots was significantly smaller, suggesting greater leaf area duration. It might thus be concluded that replacement of inorganic inputs by organic in combination with AMF inoculation, would not enhance the risk of an open canopy (that could lead to an appreciably greater loss in assimilation and productivity) and should be seriously taken into consideration as a sustainable practice.

\section{b) Biomass production}

Results suggest that both AMF inoculation and especially fertilization level had a significant effect $(\mathrm{P}<0.05)$ on barley biomass production during growth, as well as on final dry yield (Tab.1). Fertilization type (organic or inorganic) had also a significant effect, with both fertilization types appearing to be equally able to produce high level of biomass and seed yields for barley. The crop showed similar growth rates during the first days of the vegetative stage (15-20 days) for all treatments, according to the growth rates for height and apparently for the same reasons. After that period (40 DAE) and until the end of anthesis crop growth rates increased rapidly with obvious different between treatments. During the seed filling period until maturity, the crop increased with lower growth rates but similar mean differences of biomass accumulation among treatments were recorded. Final harvest took place on physiological maturity and barley productivities were significantly higher for $100 \%$ fertilized plots, regardless type of fertilizer or AMF inoculation (Tab. 1.). Total biomass production was a result of a steady seed/straw ratio, accordingly to crop Harvest Index, which was not affected by any treatment. Plants of inoculated plots reached higher seed yield by higher production in terms of seed weight.

Regarding fertilization effect on total biomass production, results demonstrated statistically significant differences on both fertilization type and fertilization rate treatments. The amount as well as the type of the applied inputs had a significant effect on total biomass production and its components. Seed yield and straw yield were higher for $100 \%$ dose of fertilization and for

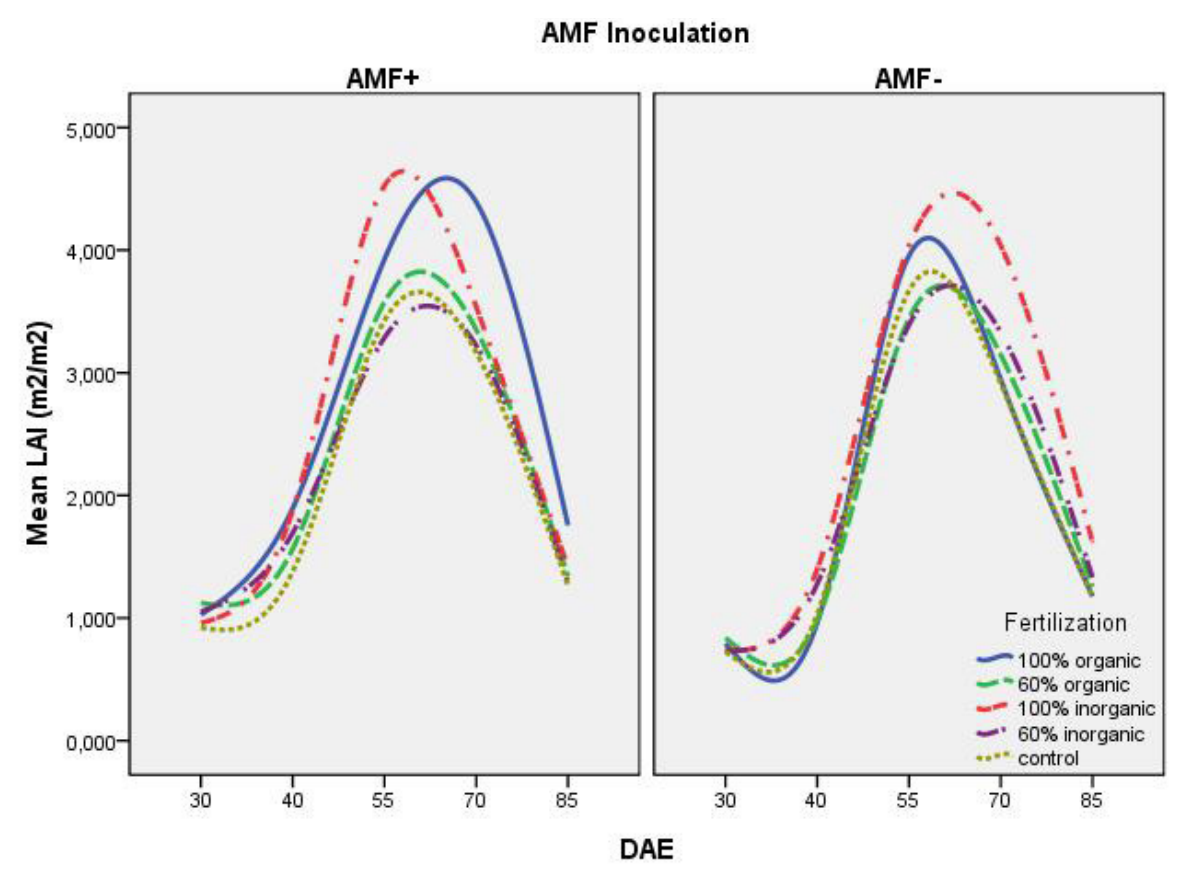

Fig. 2. Leaf Area Index of barley plants as affected by AMF inoculation and fertilization type and level. 
organic type (Tab.1), reflecting barley's response to NPK fertilization.

\section{c) AMF colonization and WMD}

According to the results of statistical analysis, AMF inoculation had a significant effect on all measured parameters of estimating mycorrhizal colonization, for both organic and inorganic fertilized plots, while no interaction inoculation $\mathrm{x}$ fertilization were detected.

As depicted in Fig.3(a) in plots that inoculation was applied, a clear confirmation that enriching AMF species will lead to positive effect on root colonization was evidenced. AMF inoculation practically doubled root colonization compared to native AMF population effectiveness. Root colonization by native or introduced AMF was negative correlated with the level of inputs, especially for the inorganic form. The negative effect of organic inputs was smaller for both levels of $100 \%$ and $60 \%$ and for both native and introduced AMF. The negative correlation between the level of fertilization and the percentage of root colonization is also reflected by the declining values of weighted mycorrhizal dependency (WMD) in Fig.3(b). For inorganic fertilization,
WMD values were declining with higher rates than for organic fertilization as fertilization level increased. WMD was higher for the 60\% NPK dose for both organic and inorganic type of fertilization.

\section{CONCLUSIONS}

In the presentresearch work, we demonstrated that AMF inoculation can positively affect growth and productivity of barley, in both organic and conventional cultivation. Results demonstrated that plants of inoculated plots exhibited greater final heights, greater leaf area expansion and duration, leading to higher final seed yields. Finally, all the parameters of the root system (AMF root colonization, mycorrhizal dependency) were negatively influenced by fertilization level, especially in an inorganic form.

Acknowledgments. This research project was funded under the Action "Research \& Technology Development Innovation projects (AgroETAK)", MIS 453350, in the framework of the Operational Program "Human Resources Development". It was co-funded by the European Social Fund and by National Resources through the National Strategic Reference Framework 2007-2013 (NSRF 2007-

Tab. 1. Influence of AMF inoculation (AMF+: with inoculation, AMF-: without inoculation) and fertilization application (rate and type) on grain yield, straw yield, total biomass production and harvest index of barley.

\begin{tabular}{|c|c|c|c|c|c|c|}
\hline & \multicolumn{3}{|c|}{ Inoculation } & \multicolumn{3}{|c|}{ Inoculation } \\
\hline & $\mathrm{AMF}+$ & AMF- & Mean & $\mathrm{AMF}+$ & AMF- & Mean \\
\hline Fertilization & \multicolumn{3}{|c|}{ Grain yield $\left(\mathrm{gr} \mathrm{m}^{-2}\right)$} & \multicolumn{3}{|c|}{ Straw yield $\left(\mathrm{gr} \mathrm{m}^{-2}\right)$} \\
\hline $100 \%$ organic & 434.53 & 424.67 & $429.60 a$ & 331.17 & 313.42 & $322.30 \mathrm{a}$ \\
\hline $60 \%$ organic & 412.00 & 405.20 & $408.60 \mathrm{~b}$ & 323.08 & 289.41 & $301.75 \mathrm{ab}$ \\
\hline $100 \%_{\text {inorganic }}$ & 402.67 & 412.00 & 422.33ab & 332.14 & 321.92 & $327.03 a$ \\
\hline $60 \%{ }_{\text {inorganic }}$ & 401.20 & 362.40 & $381.80 \mathrm{c}$ & 291.15 & 263.09 & $277.12 \mathrm{~b}$ \\
\hline control & 354.00 & 310.67 & $332.33 d$ & 258.41 & 209.48 & $233.95 c$ \\
\hline \multirow[t]{2}{*}{ Mean } & 406.88 & 382.97 & $(21.00)^{* a}$ & 307.19 & 277.67 & $(29.52)^{*}$ \\
\hline & \multicolumn{3}{|c|}{ Total biomass $\left(\mathrm{gr} \mathrm{m}^{-2}\right)$} & \multicolumn{3}{|c|}{ Harvest index (\%) } \\
\hline $100 \%$ organic & 765.70 & 738.09 & $751.89 a$ & 56.82 & 57.69 & $57.26 \mathrm{a}$ \\
\hline $60 \%$ organic & 735.08 & 685.61 & 710.35a & 56.03 & 59.10 & $57.56 \mathrm{a}$ \\
\hline $100 \%_{\text {inorganic }}$ & 764.81 & 733.92 & $749.37 \mathrm{a}$ & 56.63 & 58.19 & $56.41 \mathrm{a}$ \\
\hline $60 \%_{\text {inorganic }}$ & 692.35 & 625.49 & $658.92 \mathrm{~b}$ & 58.04 & 58.09 & $58.06 \mathrm{a}$ \\
\hline control & 612.41 & 520.15 & $566.28 \mathrm{c}$ & 57.89 & 59.72 & $58.80 \mathrm{a}$ \\
\hline Mean & 714.07 & 660.65 & $(51.43)^{*}$ & 57.08 & 58.16 & $n s^{b}$ \\
\hline
\end{tabular}

Means followed by same letter in a column are not statistically different

a* (in a row): Significant at $\mathrm{P}=0.05, \mathrm{LSD}_{0.05}$ also shown in parenthesis.

${ }^{b}$ ns (in a row): not significant at $\mathrm{P}=0.05$ 

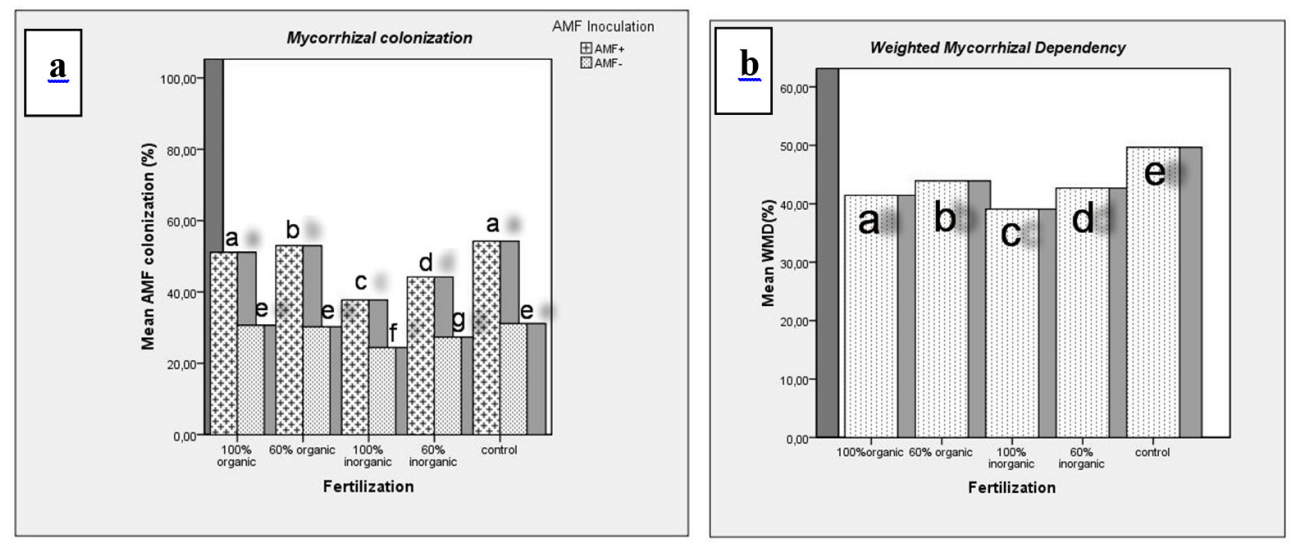

Fig 3. (a) Root colonization (\%) by AMF as affected by inoculation and fertilization type and level. (b) Weighed mycorrhizal dependency (\%) as affected by fertilization type and level. 2013) coordinated by the Hellenic Agricultural
Organisation "DEMETER".

\section{REFERENCES}

1. Azcón-Aguilar C, Barea JM (1997). Applying mycorrhiza biotechnology to horticulture, significance and potentials. Scientia Horticulturae 68:1-24.

2. Estaïn V, Camprubv A, Joner EJ (2002). Selecting arbuscular mycorrhizal fungi for field application. . In S. Gianinazzi, H. Schóepp, J. M. Barea and K. Haselwandter (Eds.), Mycorrhiza Technology in Agriculture, from Genes to Bioproducts (pp. 249-259). Basel, Switzerland.

3. Feddermann N, Roger Finlay R, Boller T, Elfstrand M (2010). Functional diversity in arbuscular mycorrhizathe role of gene expression, phosphorous nutrition and symbiotic efficiency. Fungal Ecol 3:1-8.

4. Galvez L, Douds Jr DD, Drinkwater LE, Wagoner P (2001). Effect of tillage and farming system upon VAM fungus populations and mycorrhizas and nutrient uptake of maize. Plant Soil 118: 299-308.

5. Giovannetti M, Mosse B (1980). An evaluation of techniques for measuring vesicular-arbuscular mycorrhizal infection in roots. New Phytol 84:489-500.

6. Gosling P, Hodge A, Goodlass G, Bending GD (2006). Arbuscular mycorrhizal fungi and organic farming. Agriculture, Ecosystems and Environment 113;17-35.

7. Helgason T, Daniell TJ, Husband R, Fitter AH, Young JPW (1998). Ploughing up the wood-wide web? Nature 394431.

8. Hunt R (1978). Plant Growth Analysis. Edward Arnold, London.

9. Kahiluoto H, Ketoja E, Vestberg M (2009). Contribution of arbuscular mycorrhiza to soil quality in contrasting cropping systems. Agriculture, Ecosystems and Envir 134:36-45.

10. Kogelmann WJ, Lin HS, Bryant RB, Beege DB, Wolf AM, Petersen GW (2004). A statewide assessment of the impacts of phosphorus- index implementation in Pennsylvania. J. Soil Water Conserv. 59: 9-18.

11. Kormanik PP, McGraw AC (1982). In: Schenck NC (Ed) Methods and principles of mycorrhizal research. Am. Phytopathol. Soc., St. Paul, p. 37-45.

12. Menéndez AB, Scervino JM, Godeas AM (2001). Arbucular mycorrhizal populations associated with natural and cultivated vegetation on a site of Buenos Aires province, Argentina. Biol. Fertil. Soil 33: 373-381.

13. Miransari M (2011). Interactions between arbuscular mycorrhizal fungi and soil bacteria. Appl Microbiol Biotechnol 89:917-930.

14. Plenchette C, Fortm JA, Furlan V (1983). Growth response of several plant species to mycorrhizae in a soil of moderate $\mathrm{P}$ fertility. I. Mycorrhizal dependency under field conditions. Plant Soil 70:199- 209.

15. Schussler A, Schwarzott D, Walker C (2001). A new fungal phylum, the Glomeromycota: phylogeny and evolution. Mycol. Res. 105: 1413- 1421.

16. Steel RDG., Torrie JH (1982). Principles and Procedure of Statistics. A Biometrical Approach, 2nd ed. McGraw-Hill, Inc, p. 633.

17. Vosatka M, Dodd JC (2002). Ecological considerations for successful application of arbuscular mycorrhizal fungi inoculum. In S. Gianinazzi, H. Schóepp, J. M. Barea and K. Haselwandter (Eds.), Mycorrhiza Technology in Agriculture, from Genes to Bioproducts (pp. 235-247). Basel, Switzerland. 